f E D E R L E N ER G Y MANAGE MENT PROG RA M

\title{
Partnerships with the U.S. Postal Service
}

\author{
Multiple partnerships help save energy at postal facilities
}

\section{Overview}

The U.S. Postal Service (USPS) is working to increase energy efficiency and reduce energy consumption at postal facilities. Recent successes include joint ventures with two utilities, Consolidated Edison of New York in Jamaica, New York, and Baltimore Gas and Electric (BGE), in Baltimore, Maryland. Although both ventures were motivated by national energy savings requirements for Federal facilities, the nature of the USPS-to-utility relationship differed in each agreement.

Con Edison offered a full range of services for a single facility, including engineering and financial assistance. BGE helped oversee and carry out a range of efficiency measures at multiple facilities, providing energy analysis, engineering, and financial assistance. In Baltimore, the USPS received additional technical assistance from various programs offered by the U.S. Environmental Protection Agency (EPA). Both approaches yielded significant savings, cutting energy consumption by as much as $44 \%$ in each location. Total annual savings are estimated at more than $\$ 460,000$.

\section{Background}

The Energy Policy Act of 1992 (EPAct) and Executive Order 12902 (EO 12902—now superseded by EO 13123) direct all Federal agencies to achieve a 30\% reduction in energy consumption by 2005 (compared with 1985 consump-tion levels). Before the enactment of EPAct and EO 12902, the USPS was already engaged in contracting for energy-efficient goods and services. As an independent Federal authority, it has participated in various energysaving contracts since the late 1980s. USPS regional managers also realized the advantage of new opportunities offered both by local utilities and new Federal programs. USPS facility managers in Jamaica, New York, and Baltimore, Maryland, took the initiative to explore potential energy savings and establish valuable partnerships with their local utilities in the process.

\section{Project summary}

\section{Jamaica, New York}

The Jamaica Post Office completely retrofitted its facility's chiller and lighting systems, saving energy and improving the work environment. Con Edison provided expertise and assistance, including technical advice, engineering, and financing. Con Edison was also involved in the construction and installation and now monitors the completed project and continues to verify savings.

The USPS-Con Edison joint venture will save 695,000 kilowatt-hours and \$91,000 in avoided energy costs annually. The estimated simple payback period for the project is 7.1 years.

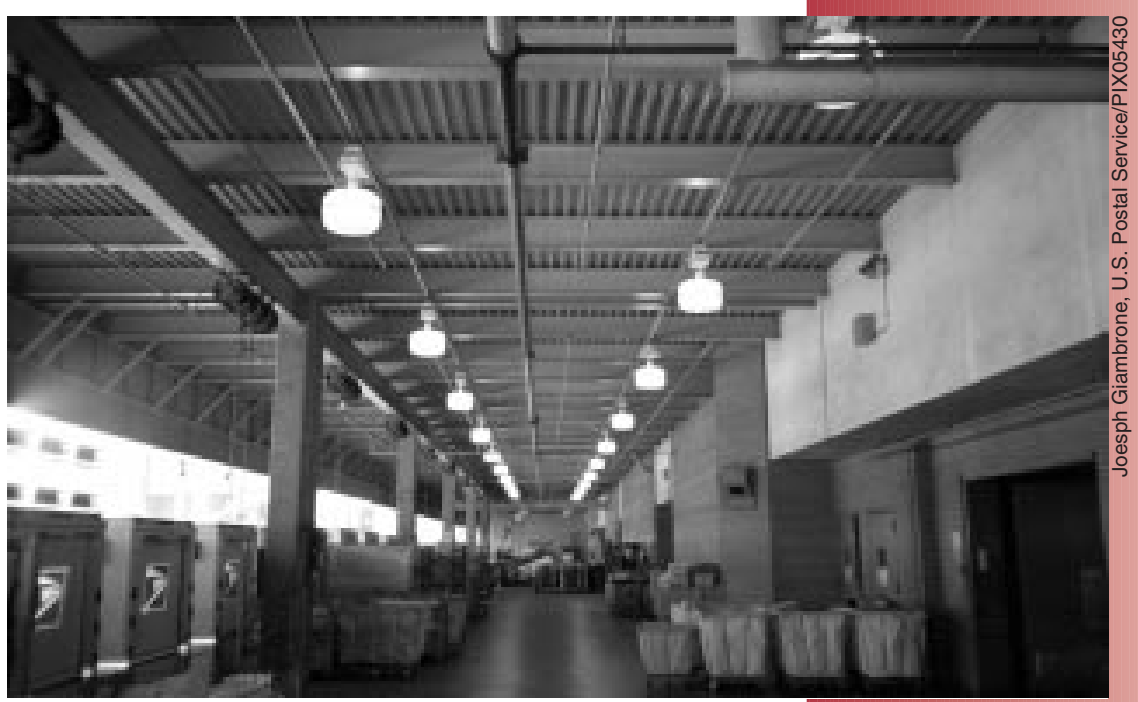

Lighting retrofits in Baltimore USPS facilities are more energy efficient and effective.

\section{Baltimore, Maryland}

In Baltimore, USPS maintenance managers joined with the EPA to save energy and money at 12 USPS facilities having a total area of more than 4 million square feet (0.37 million square meters). USPS Baltimore managers signed a memorandum of understanding with the EPA formalizing the savings process. An initial assessment by EPA engineers identified lighting improvements. Subsequent steps involved building "tune-ups," including preventive maintenance and training; a load reduction program; heating, ventilating, and air-conditioning (HVAC) distribution system upgrades; and HVAC plant upgrades.

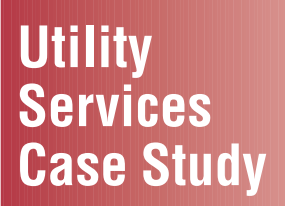

Utility Case Study 
A joint venture with BGE made achieving each step possible. BGE helped provide engineering and technical assistance for everything from installing motion-sensing photocell technology for interior lighting to converting oil-fired boilers and furnaces to natural gas and installing geothermal technology. The USPS-BGE joint venture will save more than 7.2 million kilowatt-hours and $\$ 370,000$ in total avoided energy costs annually.

\section{Benefits of utility contracting}

For both Jamaica and Baltimore, the utilities provided key technical and financial resources. By upgrading and improving lighting, insulation, HVAC, and other systems, the USPS obtained energy and economic savings and enhanced the quality of life in its facilities. Noting the improved lighting at the Jamaica facility, one USPS employee commented, "It feels like sunshine every time I walk in; it just gives me more energy to work."

\section{Lessons learned}

\section{Various types of partnerships}

The New York and Baltimore cases show that effective utility partnerships can take different forms as circumstances and needs dictate. At the Jamaica facility, managers obtained a full range of energy services from the local utility. In Baltimore, the utility was closely involved in implementing energy-saving measures, while the EPA helped with the initial assessment and strategizing.

\section{Multiple facilities under one contract}

The Baltimore case shows that utilities can be effective partners for bringing energy services to multiple facilities in a region. Development of a standard multiple-facility utility contract for regional USPS managers should help future projects.

\section{Many sources of expertise}

The Baltimore USPS tapped the resources of the local utility and various programs of the EPA, demonstrating how facility managers can draw on a range of resources and expertise. Moreover, many utilities are well versed in working with state and Federal agencies and can help managers pull information and expertise from multiple sources.

\section{Looking ahead}

Based on the success of these shared energy-savings partnerships, the USPS headquarters in Baltimore estimates $\$ 100$ million in construction costs and related energy savings can be achieved through similar projects at more than 300 USPS facilities in the Maryland area. BGE and other utilities are
Facilities meeting or exceeding reduction targets

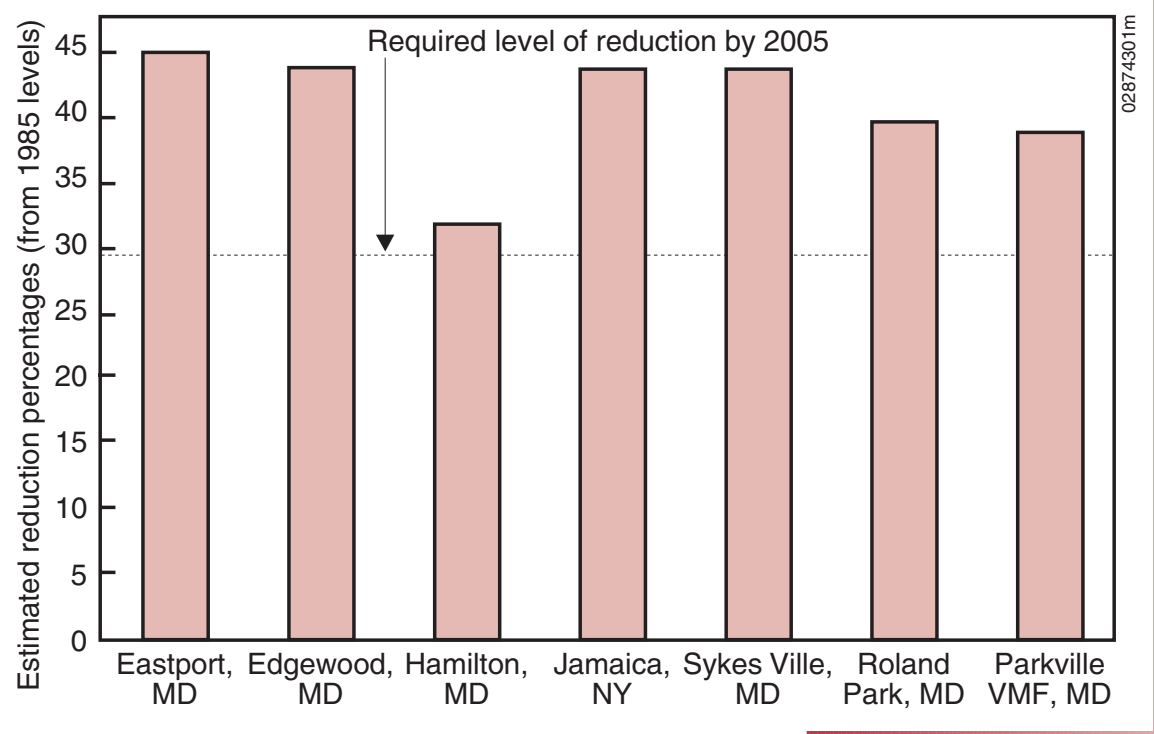

expected to be partners on 100 more projects estimated at $\$ 20$ million during the next 2 years.

Nineteen additional USPS facilities will also receive energy efficiency upgrades in the Jamaica area.

\section{For More Information}

FEMP Help Desk:

(800) DOE-EREC (363-3732)

Fax: (202) 586-3000

Internet: http:/ /www.eren.doe.gov/femp

Brad Gustafson

Utility Services Program Manager

DOE FEMP

(202) 586-2204

USPS, Baltimore:

Gary Dunaway, Manager for Field Maintenance

Operations

(410) 347-4676

Joseph Giambrone, Maintenance Manager

(410) 347-4555

USPS, Jamaica:

Victor Arroyo, Maintenance and Operations

Manager

(718) 990-1125
FEMP Help Desk:

800-DOE-EREC

(363-3732)

Internet:

http://www.eren.doe. gov/femp

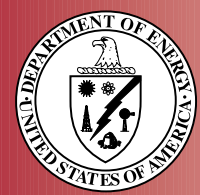

Produced for the

U.S. Department

of Energy by the

National Renewable

Energy Laboratory,

a DOE national

laboratory

DOE/GO-102000-1098 